\title{
Regioselective Nitration of Inactive 4,4-Dibromobiphenyl with Nitrogen Dioxide and Molecular Oxygen over Zeolites: An Efficient Preparation of 4,4'-Dibromo-2-nitrobiphenyl
}

\author{
Wei Wang, Xinhua Peng*, and Nan Chen \\ School of Chemical Engineering, Hefei University of Technology, No.193, Tunxi Road \\ Hefei City 230009, Anhui Province, P. R. China. *E-mail: orgpeng@gmail.com \\ (Received September 22, 2013; Accepted December 12, 2013)
}

\begin{abstract}
In the presence of zeolites, 4,4'-dibromobiphenyl could be region-selectively nitrated by the action of nitrogen dioxide and molecular oxygen. The ratio of 4,4'-dibromo-2-nitrobiphenyl to 4,4'-dibromo-3-nitrobiphenyl could reach 14 in a high yield of $90 \%$. Zeolites could be easily regenerated by heating and reused four times to give the results similar to those obtained with fresh catalyst. Compared with the classic nitration method, no nitric acid and sulfuric acid were used, which suggested that the method was an environmentally economic process.
\end{abstract}

Key words: 4,4'-Dibromobiphenyl, 4,4'-Dibromo-2-nitrobiphenyl, Nitration, Nitrogen dioxide, Zeolite

\section{INTRODUCTION}

Electrophilic nitration of aromatics is a fundamental reaction in the preparation of intermediates of many compounds including pharmaceuticals, dyestuffs, explosives, pesticides, and so on. ${ }^{1}$ The mechanistic and synthetic aspects of nitration chemistry have been studied over these years. However, many traditional processes suffer from serious disadvantages, including low selectivity for the desired product and the requirement for large quantities of mineral or Lewis acids as activators. ${ }^{2}$ Major efforts are therefore being made to develop processes with lower environmental impact.

Among a number of efforts on developing alternative methodologies, the combined use of nitrogen dioxide and molecular oxygen in the place of the classical nitric acidsulfuric system appears to be the most attractive and promising. ${ }^{3}$ Suzuki has reported that nitrogen dioxide is activated to react with a wide variety of nonactivated and moderately activated aromatic substrates to afford the corresponding nitro compounds in good yields. ${ }^{4}$ We have reported that 1-nitronaphthalene, naphthonitriles and methylated benzonitriles could be smoothly nitrated in the presence of zeolites by the combined action of nitrogen dioxide and molecular oxygen. ${ }^{5}$ The use of solid acid catalysts is a very attractive alternative to improve regioselectivity because of the case of separation, recyclability of the catalysts. ${ }^{6}$ 4,4'-Dibromo-2-nitrobiphenyl is an important fine chemical with a constantly increasing world market owing to its usefulness as synthetic intermediates. ${ }^{7}$ The present work deals with an efficient and high-selective preparation of the nitrated 4,4'-dibromobiphenyl with a nitrogen dioxide/ molecular oxygen process.

\section{EXPERIMENTAL}

\section{Regents and Apparatus}

Zeolites were purchased from New Materials Research Center of Tianjin in China. Melting points were determined on a WRS-2 apparatus and uncorrected. ${ }^{1} \mathrm{H}$ NMR and ${ }^{13} \mathrm{C}$ NMR spectra were recorded on a Agilent VNMRS$600 \mathrm{MHz}$ spectrometer (at 600 and $151 \mathrm{MHz}$, respectively) with TMS as internal standard. Chemical shifts $(\delta)$ were expressed and coupling constants $J$ were given in Hz. Infrared (IR) spectra were recorded on a Thermo Nicolet 67 Fourier transform (FT)-IR spectrometer as KBr pellets. High resolution mass spectra (HRMS) data were obtained using a Waters ACQUITY UP mass spectrometer with ESI source. TLC was performed with silica gel GF254 percolated on class plates, and spots were visualized with UV. Shimadzu GC-2014C (WONDACAP-1 df $=1.5 \mu \mathrm{m} \times$

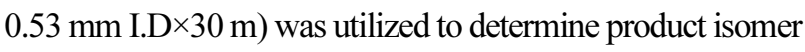
compositions with 4-nitrotoluene as internal standard. The injector and flame ionization detector were set at $280^{\circ} \mathrm{C}$. The $\mathrm{GC}$ column was operated from 140 to $250^{\circ} \mathrm{C}$ at a rate of $10{ }^{\circ} \mathrm{C} / \mathrm{min}$, and held the final temperature for $3 \mathrm{~min}$. All other chemicals were analytical grade without any further purification. 


\section{Typical Experimental Procedure for Zeolite Cation- exchange}

The standard procedure for cation-exchange involved stirring a supplied commercial zeolite $(2.50 \mathrm{~g})$ in a refluxing aqueous solution of the corresponding metal chloride $(0.2 \mathrm{~mol} / \mathrm{L}, 50 \mathrm{~mL})$ for $24 \mathrm{~h}$. The solid was filtrated, washed with deionized water until halide-free and dried at $110^{\circ} \mathrm{C}$ for $6 \mathrm{~h}$, and then calcined in air at $550{ }^{\circ} \mathrm{C}$ for $6 \mathrm{~h}$.

\section{Nitrate Progress with Nitrogen Dioxide/molecular Oxy- gen}

Quantitative 4,4'-dibromobiphenyl, nitrogen dioxide, zeolite, and dichloromethane were placed in a flask. Oxygen was passed into the system to replace air, and a balloon filled with oxygen was connected. The mixture was stirred at a certain temperature and progress of the reaction was monitored by TLC with pure petroleum ether as eluent. The Rf values of 4,4'-dibromobiphenyl and 4,4'-Dibromo2-nitrobiphenyl are 0.75 and 0.31 , respectively.

When the reaction was complete, excess nitrogen dioxide was removed by blowing air into the solution and collected in a cold trap for reuse. The zeolite was removed by filtration and the filter liquor was washed with water, $5 \%$ aqueous solution of sodium bicarbonate followed by water. The organic phase separated was dried with anhydrous sodium sulfate, and concentrated under reduced pressure to give a yellow solid residue. The product was analyzed by GC. The yellow solid with further purifica- tion was analyzed. The used zeolite was recovered by washing and calcination.

\section{4,4-Dibromo-2-nitrobiphenyl}

Yellow solid mp $125.1-125.8{ }^{\circ} \mathrm{C}$ (lit. ${ }^{8} \mathrm{mp} 125-126^{\circ} \mathrm{C}$ ) IR $(\mathrm{KBr}) v=1535\left(\mathrm{NO}_{2}\right), 785(\mathrm{C}-\mathrm{Br}) \mathrm{cm}^{-1}$. ${ }^{1} \mathrm{HNMR}$ $\left(\mathrm{CDCl}_{3}, 600 \mathrm{MHz}\right) \delta 8.02(\mathrm{~s}), 7.55(\mathrm{~d}, J=8.4 \mathrm{~Hz}, 2 \mathrm{H})$, $7.28(\mathrm{~d}, J=8.2 \mathrm{~Hz}, 2 \mathrm{H}), 7.14(\mathrm{~d}, J=8.2 \mathrm{~Hz}, 2 \mathrm{H}) .{ }^{13} \mathrm{CNMR}$ (DMSO, $151 \mathrm{MHz}) \delta 152.37,138.91,138.32,136.56$, 136.15, 134.87, 133.02, 129.90, 125.26, 124.36. HRMS (ESI) for $\mathrm{C}_{12} \mathrm{H}_{7} \mathrm{Br}_{2} \mathrm{NO}_{2}$ calcd 364.8844 found 364.8841 .

\section{RESULTS AND DISCUSSION}

From Table 1, nitration of 4,4'-dibromobiphenyl 1 with traditional nitric acid and nitrosulfuric acids gave a mixture of 4,4'-dibromo-2-nitrobiphenyl 2 and 4,4'-dibromo3-nitrobiphenyl 3 in the isomer ratio of 2.5 and 3.8 (Entries 1 and 2 in Table 1) in yield of 70 and 38\%, respectively. Dinitrated products were predominant in nitrosulfuric acids process. However, reaction could be mildly conducted at the combined action of nitrogen dioxide and molecular oxygen. When the amount of nitrogen dioxide increasing, the reaction towards good mononitrated yield in high region-selection up to a ratio of 6.0-9.0 above in 2 to 3 (Entries 5-7 in Table 1) and 4,4'-dibromo-2-nitrobiphenyl 2 was efficiently formed in over $70 \%$ yield.

It was also found that catalysts played an important role

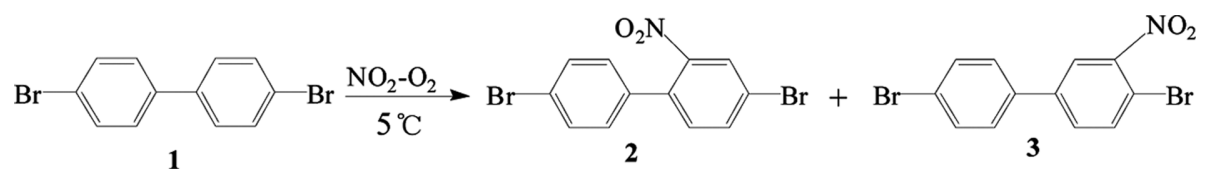

Scheme 1.

Table 1. Nitration of 4,4-dibromobiphenyl with acid or $\mathrm{NO}_{2}-\mathrm{O}_{2}$

\begin{tabular}{|c|c|c|c|c|c|c|c|}
\hline \multirow{2}{*}{ Entry } & \multirow{2}{*}{ Nitrating agent ${ }^{\mathrm{a}}$} & \multirow{2}{*}{ Reation time/h } & \multirow{2}{*}{ Conversion $(\%)$} & \multirow{2}{*}{ Yield (\%) } & \multicolumn{2}{|c|}{ Isomer proportion } & \multirow{2}{*}{$\begin{array}{r}2: 3 \\
\text { Ratio }\end{array}$} \\
\hline & & & & & 2 & 3 & \\
\hline 1 & $\mathrm{HNO}_{3}{ }^{\mathrm{b}}$ & 8 & 75 & 70 & 50 & 20 & 2.5 \\
\hline 2 & $\mathrm{HNO}_{3}-\mathrm{H}_{2} \mathrm{SO}_{4}{ }^{\mathrm{c}}$ & 3 & 100 & 38 & 30 & 8 & 3.8 \\
\hline 3 & $\mathrm{NO}_{2}-\mathrm{O}_{2}(1: 2)$ & 24 & 31 & 28 & 18 & 10 & 1.8 \\
\hline 4 & $\mathrm{NO}_{2}-\mathrm{O}_{2}(1: 4)$ & 12 & 57 & 53 & 35 & 18 & 1.9 \\
\hline 5 & $\mathrm{NO}_{2}-\mathrm{O}_{2}(1: 6)$ & 10 & 78 & 70 & 60 & 10 & 6.0 \\
\hline 6 & $\mathrm{NO}_{2}-\mathrm{O}_{2}(1: 8)$ & 10 & $>99$ & 79 & 71 & 8 & 8.9 \\
\hline 7 & $\mathrm{NO}_{2}-\mathrm{O}_{2}(1: 10)$ & 6 & 100 & 80 & 72 & 8 & 9.0 \\
\hline 8 & $\mathrm{NO}_{2}-\mathrm{O}_{2}(1: 12)$ & 6 & 100 & 81 & 72 & 9 & 8.0 \\
\hline 9 & $\mathrm{NO}_{2}-\mathrm{O}_{2}(1: 14)$ & 6 & 100 & 81 & 73 & 8 & 9.1 \\
\hline
\end{tabular}

${ }^{\mathrm{a}}$ The data in parentheses meant a molar ratio of nitrogen dioxide to $4,4^{\prime}$-dibromobiphenyl.

${ }^{\mathrm{b}}$ There action was carried out in dichloromethane $(5.0 \mathrm{~mL})$ using $\mathbf{1}(1.0 \mathrm{mmol}), 95 \%$ nitric acid $(2.0 \mathrm{mmol})$.

${ }^{\mathrm{c}}$ The reaction was conducted in dichloromethane $(5.0 \mathrm{~mL})$ using $1(1.0 \mathrm{mmol}), 95 \%$ nitric acid $(1.5 \mathrm{mmol})$ and $98 \%$ sulfuric acid $(1.5 \mathrm{mmol})$. 


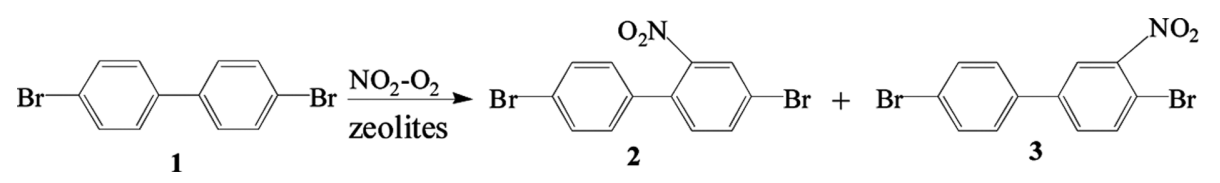

Scheme 2.

Table 2. Nitration of 4,4-dibromobiphenyl with nitrogen dioxide/molecular oxygen in the presence of zeolite catalysts ${ }^{\mathrm{a}}$

\begin{tabular}{|c|c|c|c|c|c|c|c|}
\hline \multirow{2}{*}{ Entry } & \multirow{2}{*}{ Catalyst $^{\mathrm{b}}$} & \multirow{2}{*}{ Reaction time/h } & \multirow{2}{*}{ Conversion $^{\mathrm{c}}(\%)$} & \multirow{2}{*}{ Yield $^{\mathrm{d}}(\%)$} & \multicolumn{2}{|c|}{ Isomer proportion $(\%)^{\mathrm{e}}$} & \multirow{2}{*}{$\begin{array}{l}2: 3 \\
\text { Ratio }\end{array}$} \\
\hline & & & & & 2-Nitro 2 & 3-Nitro 3 & \\
\hline $1^{\mathrm{f}}$ & - & 10 & 39 & 34 & 27 & 7 & 3.9 \\
\hline $2^{\mathrm{f}}$ & HBEA-25 & 10 & 93 & 87 & 78 & 9 & 8.7 \\
\hline $3^{\mathrm{g}}$ & - & 12 & 53 & 48 & 40 & 8 & 5.0 \\
\hline $4^{\mathrm{g}}$ & - & 24 & 97 & 89 & 80 & 9 & 8.9 \\
\hline 5 & - & 10 & 76 & 70 & 60 & 10 & 6.0 \\
\hline 6 & HBEA-25 & 10 & 100 & 88 & 80 & 8 & 10 \\
\hline 7 & BEA-280 & 10 & 98 & 88 & 82 & 6 & 14 \\
\hline 8 & BEA-500 & 10 & 100 & 89 & 81 & 8 & 10 \\
\hline 9 & HZSM-5 & 12 & 91 & 80 & 70 & 10 & 7.0 \\
\hline 10 & Fe-ZSM-5 & 12 & 100 & 90 & 84 & 6 & 14 \\
\hline 11 & Co-ZSM-5 & 12 & $>99$ & 86 & 78 & 8 & 9.8 \\
\hline 12 & La-ZSM-5 & 12 & $>99$ & 84 & 77 & 7 & 11 \\
\hline 13 & Mg-ZSM-5 & 12 & $>99$ & 90 & 80 & 10 & 8.0 \\
\hline
\end{tabular}

${ }^{\mathrm{a}}$ All reactions were carried out in dichloromethane $(5 \mathrm{~mL})$ using substrate $1(1.0 \mathrm{mmol})$, liquid $\mathrm{NO}_{2}(6.0 \mathrm{mmol})$ and catalyst $(0.2 \mathrm{~g})$. Oxygen was passed into the system to replace air, and a balloon filled with oxygen was connected. The mixture was stirred at $5{ }^{\circ} \mathrm{C}$.

${ }^{\mathrm{b}}$ Zeolites were calcined at $550{ }^{\circ} \mathrm{C}$ for $2 \mathrm{~h}$ in air prior to use.

${ }^{\mathrm{c}}$ Determined by GC.

${ }^{\mathrm{d}} \mathrm{A}$ combined yield of $\mathbf{2}$ and $\mathbf{3}$ based on consumed $\mathbf{1}$ was given.

${ }^{\mathrm{e}}$ Calculated from GC peak areas, excluding other isomers and byproducts.

${ }^{\mathrm{f}}$ Conducted in the air atmosphere.

${ }^{\mathrm{g}} 1,2$-dichloroethane was used as the solvent.

in improvement of the reaction. Smith and his coworkers had reported that halobenzenes could be nitrated with nitrogen dioxide and molecular oxygen in the presence of zeolite HBEA catalyst can give products of nitration, in which the para-nitro isomer predominates over the orthoisomer. ${ }^{9}$ While Suzuki group had reported that ZSM-5 appeared to be better catalytic selective characteristics. ${ }^{10}$ In the recent work of the Chun J Shi, superior selectivity for production of 4,4'-dibromo-2-nitrobiphenyl was achieved at low conversion catalyzed by HBEA-500 with nitric acid/acetic anhydride as nitration agent. ${ }^{11}$ In the hope of improving the selectivity of 4,4'-dibromo-2-nitrobiphenyl in the nitrogen dioxide and molecular oxygen system, hydrogen and its metal ions exchanged BEA and ZSM-5 zeolites were employed. Zeolites facilitated the reaction and gave a high yield as compared with no catalysts. Among $\mathrm{H}^{+}, \mathrm{Co}^{2+}, \mathrm{Mg}^{2+}, \mathrm{Fe}^{3+}$ and $\mathrm{La}^{3+}$ modified zeolites, FeZSM5 was observed to give the most excellent yield of $90 \%$ with 84\% 4,4'-dibromo-2-nitrobiphenyl selectivity (Entries 6-13 in Table 2). The activity of the zeolites may be due to

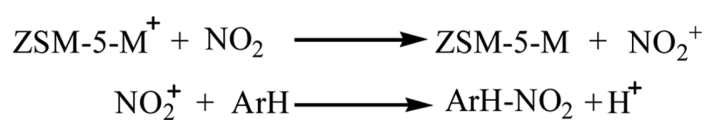

Scheme 3.

the existence of strong acid sites and metal cations, which could easily prompt the production of $\mathrm{NO}_{2}{ }^{+}$that appeared to play a positive role in attaining a higher $2: \mathbf{3}$ isomer ratio (Scheme 3).

As considering the prospects for applications, the optimization scale up procedures were investigated. The represented results were summarized in Table 3. From Table 3, the similar yields and isomers ratio had been achieved.

FeZSM- 5 could be reused by simple filtration with a little loss of original activity (Table 4). Even after four times usage there was few observed change in nitration selectivity and yield. 
Table 3. Scale-up procedures ${ }^{\mathrm{a}}$

\begin{tabular}{cccccccccc}
\hline Entry & $\begin{array}{c}\text { Amount of } \\
\text { substrate }(\mathrm{g})\end{array}$ & $\begin{array}{c}\text { Amount of } \\
\text { catalyst }(\mathrm{g})\end{array}$ & Nitrating agent ${ }^{\mathrm{b}}$ & Conversion (\%) & Yield (\%) & \multicolumn{2}{c}{ Isomer proportion } & $\begin{array}{c}\mathbf{2 : 3} \\
\text { Ratio }\end{array}$ \\
\hline 1 & 0.31 & 0.2 & $1: 6$ & 100 & 90 & 84 & 6 & 14 \\
2 & 0.62 & 0.3 & $1: 5$ & 94.5 & 88 & 82 & 6 & 14 \\
3 & 1.24 & 0.4 & $1: 4$ & 100 & 92 & 86 & 6 & 14 \\
\hline
\end{tabular}

${ }^{\mathrm{a}}$ The mixture was stirred at $5{ }^{\circ} \mathrm{C}$ for $12 \mathrm{~h}$.

${ }^{\mathrm{b}}$ The ratio in parentheses meant a molar amount in nitrogen dioxide to 4,4'-dibromobiphenyl.

Table 4. Efficiency of recycled FeZSM-5 in the nitration of 4,4'dibromobiphenyl ${ }^{\mathrm{a}}$

\begin{tabular}{cccccc}
\hline \multirow{2}{*}{ Entry } & $\begin{array}{c}\text { Conversion } \\
(\%)\end{array}$ & $\begin{array}{c}\text { Yield } \\
\text { (\%) }\end{array}$ & \multicolumn{2}{c}{ Isomer Production (\%) } & $\mathbf{2 : 3}$ \\
\cline { 4 - 5 } & 2-Nitro & 3-Nitro & Ratio \\
\hline fresh & 100 & 90 & 84 & 6 & 14.0 \\
1 & 100 & 88 & 82 & 6 & 13.7 \\
2 & 100 & 87 & 81 & 6 & 13.5 \\
3 & 100 & 87 & 80 & 7 & 11.4 \\
4 & 100 & 86 & 80 & 6 & 13.3 \\
\hline
\end{tabular}

${ }^{\mathrm{a} A l l}$ conditions were the same to Table 3 (Entry 1$)$.

\section{CONCLUSION}

Nitration of 4,4'-dibromobiphenyl with nitrogen dioxide/molecular oxygen system in the presence of zeolites could show excellent selectivity in high yield. Moreover, 4,4'-dibromo-2-nitrobiphenyl could be efficiently prepared using environmentally economic process.

Acknowledgments. The publication cost of this paper was supported by the Korean Chemical Society.

\section{REFERENCES}

1. (a) Cortona, M. N.; Vettorazzi, N.; Silber, J. J.; Sereno, L. J. Electroanal. Chem. 1995, 394, 245. (b) Halder, R.; Lawal, A.; Damavarapu, R. Catal. Today 2007, 125, 74. (c) Chaubal, N. S.; Sawant, M. R. Catal. Commun. 2007, 8, 845. (d) Belciug, M.; Ananthanarayanan, V. S. J. Med. Chem. 1994, 37, 4392.
2. (a) Smith, K.; Almeer, S.; Peters, C. Chem. Commun. 2001, 2748. (b) Samajdar, S.; Becker, F. F.; Banik, B. B. Tetrahedron Lett. 2000, 41, 8017. (c) Tasneem, M. M.; Ali, K. C.; Rajanna, Saiparakas, P. K. Synth. Commun. 2001, 31, 1123. (d) Bharadwaj, S. K.; Hussain, S.; Kar, M. Catal. Commun. 2008, 9, 919.

3. Nishiwaki, Y.; Sakaguchi, S.; Ishii,Y. J. Org. Chem. 2002, 67, 5663.

4. Suzuki, H.; Yonezawa, S.; Nonoyama, N. and Mori, T. J. Chem. Soc. Perkin Trans. 1996, 1, 2385.

5. Peng, X. H.; Fukui, N.; Mizuta, M. and Suzuki, H. Org. Biomol. Chem. 2003, 1, 2326.

6. (a) Smith, K.; Almeer, S.; Black, S. J.; Peters, C. J. Mater. Chem. 2002, 12, 3285. (b) Parac-Vogt, T. N.; Pachini, S.; Nockemann, P.; Hecke, K. V.; Meervelt, L. V.; Binnemans, K. Eur. J. Org. Chem. 2004, 4560.

7. (a) Yasutani, Y.; Honsho, Y.; Saeki, A.; Seki, S. Synth. Met. 2012, 162, 1713. (b) Kawabata, K.; Goto, H. Synth. Met. 2010, 160, 2290. (c) Ooyama, Y.; Sugiyama, T.; Oda, Y.; Hagiwara, Y. N.; Yamaguchi, E.; Miyazaki, H.; Fukuoka, T.; Harima, Y. and Ohshita, J. Eur. J. Org. Chem. 2012, 4853. (d) Freeman, A. W.; Urvoy, M.; Criswell, M. E. J. Org. Chem. 2005, 70, 5014.

8. (a) Lee, J. C.; WO 2009061145 A1, 2009, CAPLUS (b) WSS: Spectral data were obtained from Wiley Subscription Servies, Inc. (US).

9. Smith, K.; Almeer, S.; Black, S. J. Chem. Commun. 2000, 1571.

10. Peng, X.; Suzuki, H.; Lu, C. Tetrahedron Lett. 2001, 42, 4357.

11. Shi, C. J.; Tai, Y. F.; Liu, H. T. Bull. Korean Chem. Soc. 2013, 34, 3485. 